\title{
Interactive comment on "Impact of small-scale disturbances on geochemical conditions, biogeochemical processes and element fluxes in surface sediments of the eastern Clarion-Clipperton Zone, Pacific Ocean" by Jessica B. Volz et al.
}

Jessica B. Volz et al.

jessica.volz@awi.de

Received and published: 4 December 2019

Dear Prof. Dr. Jack Middelburg,

My co-authors and I are pleased to submit the final responses to the revisions for our Printer-friendly version original research article entitled "Impact of small-scale disturbances on geochemical conditions, biogeochemical processes and element fluxes in surface sediments of the eastern Clarion-Clipperton Zone, Pacific Ocean" for consideration in the special issue 
"Assessing environmental impacts of deep-sea mining - revisiting decade-old benthic disturbances in Pacific nodule areas" to Biogeosciences. We feel confident that the revisions of the two reviewers will improve the quality and impact of our manuscript. We have addressed all comments carefully in the responses attached in the Supplement.

Thank you for your time and consideration. If you have any questions, please do not hesitate to contact me and I will do my utmost to provide any further information that you require.

Yours sincerely, Jessica Volz

Please also note the supplement to this comment:

https://www.biogeosciences-discuss.net/bg-2019-316/bg-2019-316-AC1-

supplement.pdf

Interactive comment on Biogeosciences Discuss., https://doi.org/10.5194/bg-2019-316, 2019. 